\title{
信息技术在小学英语词汇教学中的运用
}

郃丽莉

昆山市开发区世茂蝶湖湾小学

DOI:10.32629/jief.v2i6.1017

[摘 要] 英语是一门非常重要的学科, 为了帮助学生打下一个良好的英语基础, 我国的教育部门在小学阶段开设了英语课程。在小学英语教 学中, 词汇教学是其中的重点内容。所有的英语知识都是通过单词的组合来体现的。学生的英语词汇量如果不足, 会对学生的英语写作、阅 读等方面的学习都造成不同程度的影响。由于小学生的年龄比较小, 英语词汇的学习非常的枯燥, 许多小学生都会英语词汇教学非常的抗拒。 这个时候老师需要转变原有的教学方法和理念, 把信息技术代入其中, 激发学生的兴趣。本文对信息技术在小学英语词汇教学中的应用进行 分析, 并且提出了几点相关性浅见。

[关键词] 信息技术; 教学方法; 小学英语词汇教学

中图分类号：G623.31 文献标识码：A

当前我国已经全面进入了信息时代，在信息时代，信息技术受到了 前所未有的重视, 各个行业在发展的过程中, 都把信息技术作为一项强 大的助力。教育领域作为我国的重点领域, 也要跟上时代发展的脚步, 积极的进行革新。在小学英语词汇教学中应用信息技术, 可以产生良好 的教学效果。下文对此进行简要的分析。

\section{1 利用信息技术激发学生兴趣}

小学生的主观性非常的强, 对于他们来说, 兴趣时他们学习的主要 动力, 如果学生对一门学科没有兴趣, 那么无论老师采用何种教学方法, 产生的教学效果都是非常有限的。老师在小学英语词汇教学中, 必须要 以学生的兴趣为导向。在传统的小学英语词汇教学中, 由于老师的教学 理念存在偏差, 在词汇教学中, 通常会让学生对一个单词进行反复的抄 写, 在检测学生词汇学习成果的时候, 如果学生不能书写正确, 老师会 让他们进行几十遍的抄写和默写。这种教学的方法会让学生产生抗拒的 心理, 不利于小学生词汇学习兴趣的提升, 会严重的降低小学英语词汇 教学的效果。在信息技术背景下, 老师要充分的发挥出信息技术的作用, 利用信息技术来提升小学生的学习兴趣。比如在学习 “friend” 这个单 词的时候, 老师可以利用信息技术对课堂内容进行拓展, 找出与这个单 词相关联的词汇, 在网络上查找一些图片给学生展示, 让学生对 “朋友” 这个单词产生更加深刻的印象, 同时, 老师可以给学生观察一些图片, 让学生观察图片上的人物, 使用一些词语来对他们进行描述, 然后老师 趁机引出一些单词, 实现小学英语词汇的拓展教学, 像 Ta11: 高大的、 Honest: 诚实的, 守信的、Faithful1: 值得信赖的、Wise: 机敏的, 睿 智的。Humorous: 幽默的, 爱开玩笑的。Neat: 穿着整洁的。

Strong: 体格健壮的。(Muscular: 强健的) Iron-wi11: 意志坚强的, 有魄力的。Zealous: 热心的, 一心一意的。Ingenious: 足智多谋的。 Popular: 受欢迎的。Gentle: 有绅士风度的, 优雅的。对于小学生来说, 静态的文字知识的吸引力是非常有限的, 而且图片和视频可以让他们产 生更加浓厚的兴趣, 利用信息技术, 可以有效的实现这样的教学目标, 对于小学生英语词汇储量的提升有很大的帮助。

\section{2 利用信息技术创设教学情境}

在小学英语词汇教学中, 老师要充分的发挥出信息技术的重要作用。 在实际的教学过程中, 老师会发现一种现象, 老师在带领大家读单词的 时候, 基本上所有的学生都可以跟上老师的朗读节奏, 但是如果老师对 单词的朗读进行细化, 让单个学生进行朗读, 有很大一部分学生都不能 正确的发音。发生这种情况的主要原因是因为学生在集体的朗读中, 他 们的没有对单词进行记忆和思考, 只是单纯的跟读。为了避免这种情况 的发生, 提升小学英语词汇教学效果, 老师可以利用信息技术为学生创
设一个教学情境, 通过老师的引导, 让学生充分的融入到这个情境中, 学生在情境中可以充分的发挥自己的思维, 注意力也会保持高度的集中。 比如老师可以以 “家庭” 作为课堂主题, 利用信息技术创设出一个家庭的 教学情境, 在网络上搜索一些家庭素材的动画片段, 让学生进行观看。学 生在观看的过程中, 会逐渐的融入到这个情境中, 老师要引导学生对其中 的单词进行记忆, 不仅样掌握单词的发音, 而且还需要掌握单词的写法。 在观看完动画片以后, 为了增强教学效果, 巩固学生的英语知识, 老师可 以让学生扮演不同的角色, 开展以家庭为主题的课堂活动。通过这样的方 式学生的学习兴趣可以得到明显的提升, 在信息技术创设的教学情境中, 学生的精神会更加的集中, 可以在短时间内掌握更多的词汇, 而且对词汇 的记忆会更加的深刻。老师在这个过程中一定要注意, 情境创设的过程中, 不能忘记初始的情境创设目的, 要注重学生词汇量的提升。

\section{3 利用游戏来开展高效小学英语词汇教学}

在之前的观念中, 游戏与学习是两个完全相反的概念, 小学生玩游 戏会严重的影响他们的学习。在信息时代, 游戏的性质已经发生的改变, 老师在小学英语词汇教学中, 可以利用游戏来提升小学英语词汇教学效 果, 激发学生的兴趣。比如老师可以把打字游戏带入到教学中, 在游戏 的开展阶段, 画面中会出现小帆船, 小帆船上会出现一些英文单词, 学 生如果能在限定的时间内完成单词的书写, 就可以得分。利用这样的方 式, 学生的学习兴趣可以得到有效的提升, 对小学生英语词汇量的提升 有很大的帮助。

\section{4 结束语}

综上所述, 小学英语词汇教学是小学阶段的重点教学内容, 对小学 生英语能力的提升有直接的影响。在传统的小学英语词汇教学中存在许 多的问题, 学生的学习兴趣不高, 老师可以利用信息技术来改善这种教 学现状, 激发学生的学习兴趣, 为学生创设出相关的教学情境, 帮助小 学生打下一个良好的英语基础, 为我国的教育事业做出积极的贡献。

\section{[参考文献]}

[1]王晓君.现代信息技术在小学英语教学中的有效运用探究[J].新 课程研究,2019(19):125-126.

[2] 李延明. 信息技术在小学英语教学中的应用 [J]. 甘肃教 育,2019(14):81.

[3]秦力. 情境教学法在小学词汇教学中的应用设计[D]. 淮北师范大 学,2019.

[4]罗佳.如何在小学英语教学中渗透信息技术[C].教育理论研究(第 九辑).重庆市鼎耘文化传播有限公司,2019:32. 